\title{
Diabetische voetzorg is multidisciplinair teamwerk
}

iabetische voetzorg vraagt om een multidisciplinaire aanpak. De in 2017 verschenen richtlijn Diabetische Voet geeft aanbevelingen voor de organisatie van de zorg, maar de praktijk wijst uit dat de uitvoering ervan op enkele punten lastig is. Met name waar het gaat om de samenwerking tussen betrokken disciplines en tijdige signalering en doorverwijzing. Op initiatief van de Nederlandse Diabetes Federatie is een werkgroep geformeerd vanuit de betrokken beroepsgroepen* en patiënten om knelpunten rond de implementatie van de multidisciplinair georganiseerde diabetische voetzorg weg te nemen. Deze werkgroep heeft de recent opgeleverde NDF-module Samenwerkingsafspraken Diabetische Voetzorg ontwikkeld, bestaande uit een aantal praktische tools die gebruikt kunnen worden als basis voor afspraken over regionale, multidisciplinaire samenwerking.

\section{MULTIDISCIPLINAIRE AANPAK}

De richtlijn Diabetische Voet beschrijft dat er in Nederland in 2015 minimaal 20.000 patiënten (bij een geschatte prevalentie van 2 tot $3 \%$ van de totale diabetespopulatie) met een voetulcus waren, bij wie bij ongeveer $15 \%$ van deze patiënten een amputatie van (een deel van) het been werd verricht. ${ }^{1,2}$ Deze ulcera hebben vaak een slechte genezingstendens met een genezingstijd van twee tot vijf maanden, hebben intensieve behandeling nodig, gaan vaak gepaard met langdurige ziekenhuisopnames en resulteren in een verlies van mobiliteit en kwaliteit van leven. Zowel voor de patiënt als het zorgsysteem is de belasting groot. In één studie was de kwaliteit van leven gelijk aan die van patiënten met een kleincellig longcarcinoom. De directe kosten van de behandeling van een voetulcus waren in Nederland in 2005 ongeveer $€ 16.000$.,4 Wetenschappelijk onderzoek heeft aangetoond dat vroegtijdige signalering van risicofactoren ernstige voetproblemen (inclusief amputatie) kan voorkomen. Multidisciplinaire samenwerking is daarbij essentieel. Er zijn veel verschillende zorgprofessionals betrokken bij de preventie en behandeling van complicaties

\section{Nathalie Ekelmans, journalist}

Correspondentie:

info@diabetesfederatie.nl aan de onderste extremiteiten bij mensen met diabetes; een multidisciplinaire benadering is nodig om ulcera, amputaties, verlies van kwaliteit van leven en kosten te voorkomen. Het is daarom van groot belang om heldere afspraken te maken over hoe de zorg wordt vormgegeven en over de taken en verantwoordelijkheden van iedere betrokken zorgprofessional. Ondanks de richtlijn Diabetische Voet worden er problemen ervaren in de uitvoering van de zorg. Deze hebben veelal te maken met het ontbreken van afstemming en goede samenwerkingsafspraken tussen betrokken zorgprofessionals en het ontbreken van duidelijke zorgpaden. Zo worden onder meer knelpunten gesignaleerd rond:

- de samenwerking en afstemming tussen huisartspraktijk, podotherapeut en voetenteam;

- de organisatie van het jaarlijkse voetonderzoek;

- patiënteneducatie en bewustwording;

- tijdige verwijzing naar en begeleiding door de juiste zorgprofessional en goede follow-up van patiënten met verhoogd risico op een recidief voetulcus.

\section{RAAMWERK VOOR SAMENWERKINGSAFSPRAKEN}

Om de in de praktijk gesignaleerde knelpunten rond de implementatie van de multidisciplinair georganiseerde diabetische voetzorg weg te nemen, kreeg de uit experts bestaande werkgroep de opdracht een raamwerk voor samenwerkingsafspraken te ontwikkelen, alsook een bijbehorend implementatieplan. Snel na installatie van de werkgroep werden de experts geconfronteerd met de onverwachte COVID-19-situatie. Tijdens de eerste fase van de pandemie kwam de zorg voor mensen met diabetes en voetproblemen onder spanning te staan; patiënten waren huiverig om naar de praktijk of het ziekenhuis te komen en betrokken zorgverleners worstelden met de vraag hoe de RIVM-richtlijnen in verhouding stonden tot het bieden van adequate voetzorg. Als reactie hierop heeft de expertgroep de multidisciplinaire leidraad Voetzorg ten tijde van COVID-19 opgesteld. ${ }^{5}$

\section{VOETZORG TIJDENS COVID-19}

In principe kan de normale preventieve voetzorg weer opgepakt worden. Wel met inachtneming van de RIVMrichtlijnen - die zeggen dat zorg in principe fysiek wordt 
Figuur 1. Spreekkamerkaart'Preventieve voetzorg' (voor- en achterkant).

Preventieve voetzorg

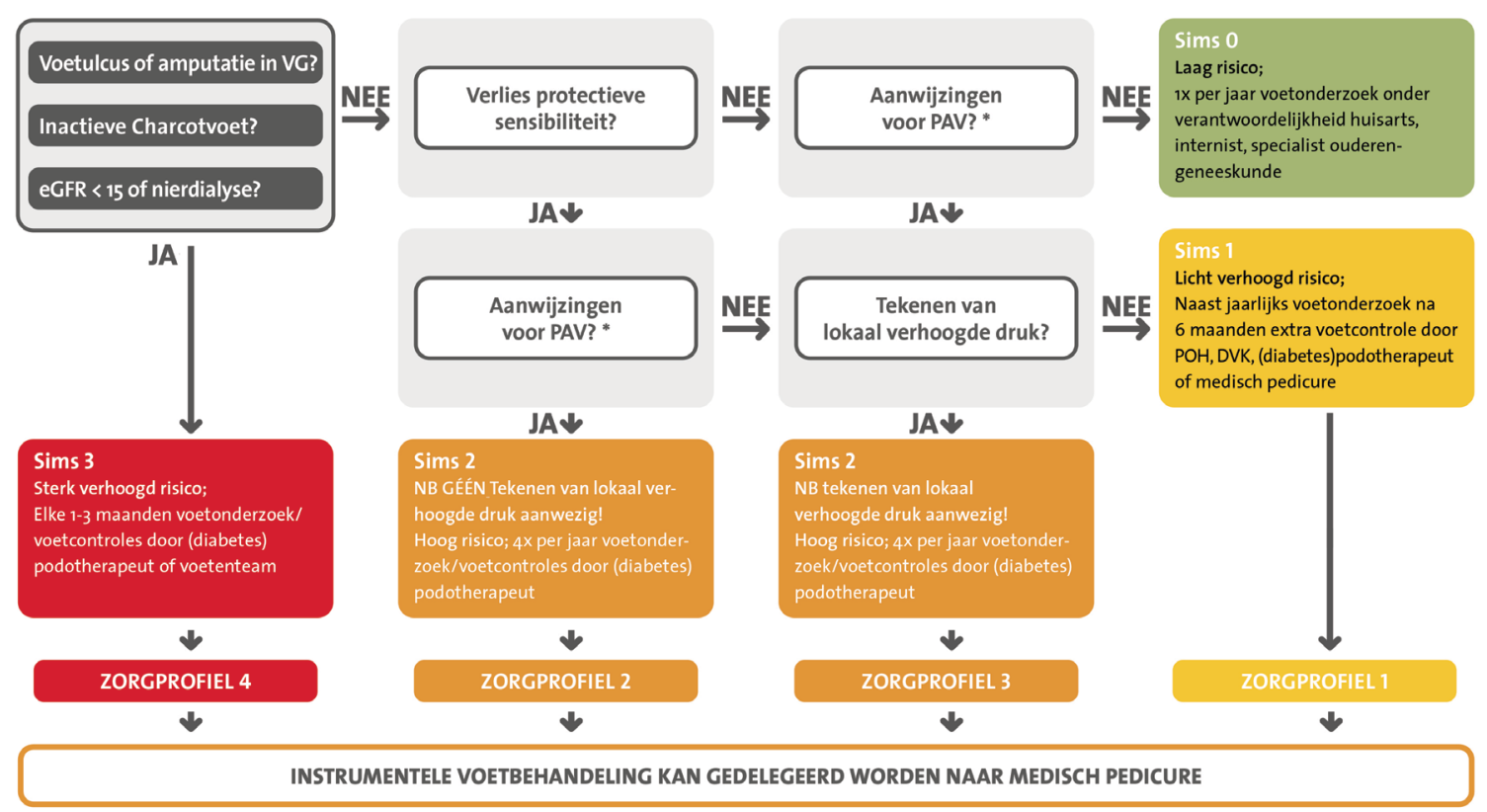

*Bij ernstige ischemie op basis van perifeer arterieel vaatlijden (PAV) dient zorgbehoefte op individuele basis door de hoofdbehandelaar van de diabetes bepaald te worden.

\section{Vaatonderzoek in eerste lijn bij afwezigheid voetulcus}

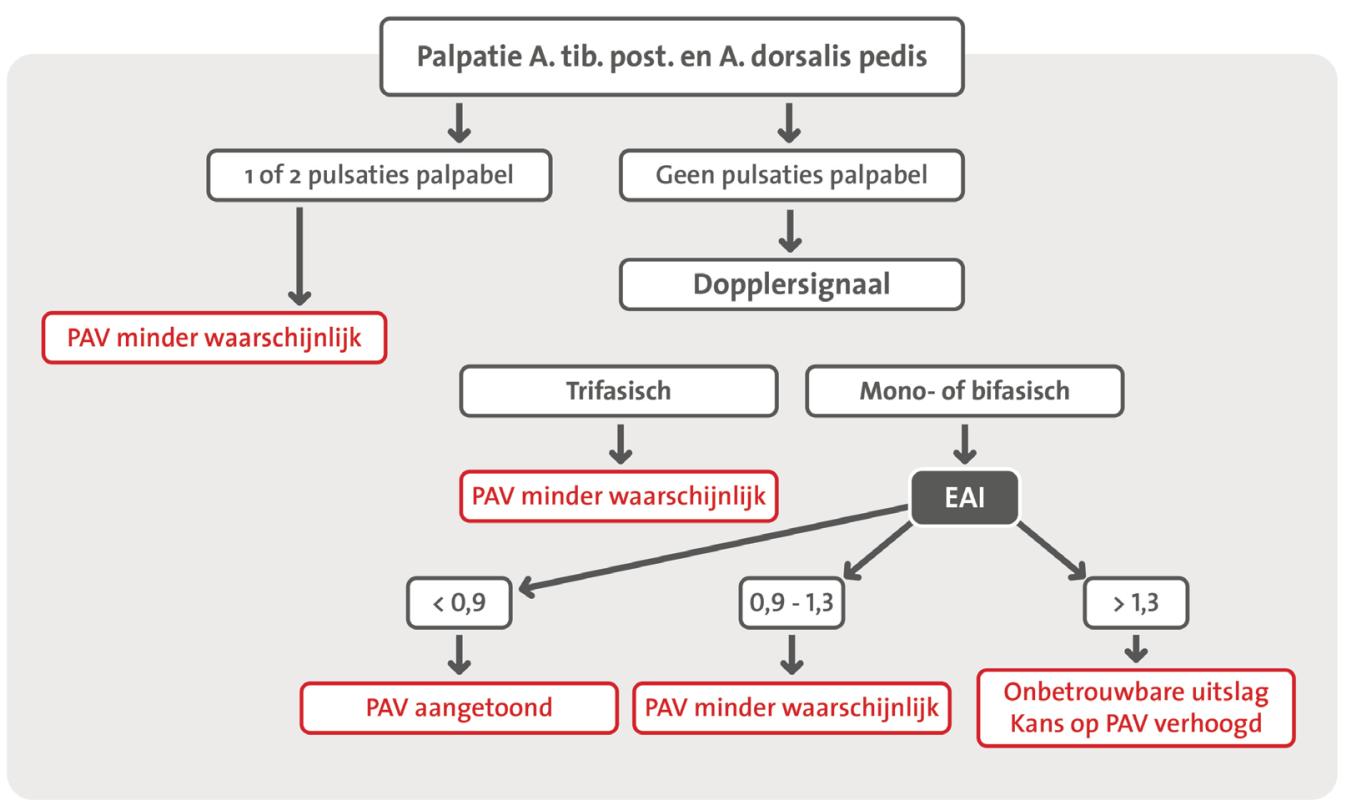

online: www.diabetesfederatie.nl/preventieve-voetzorg

geleverd - maar waarbij een gezondheidscheck vereist is. Het advies aan patiënten is om de voeten te controleren op wondjes en/of blaren en bij een wond aan de voeten direct contact op te nemen met de huisarts/praktijkondersteuner of medisch specialist/diabetesverpleegkundige (bij Sims 0 en 1) of met de behandelend podotherapeut (bij Sims 2 en 


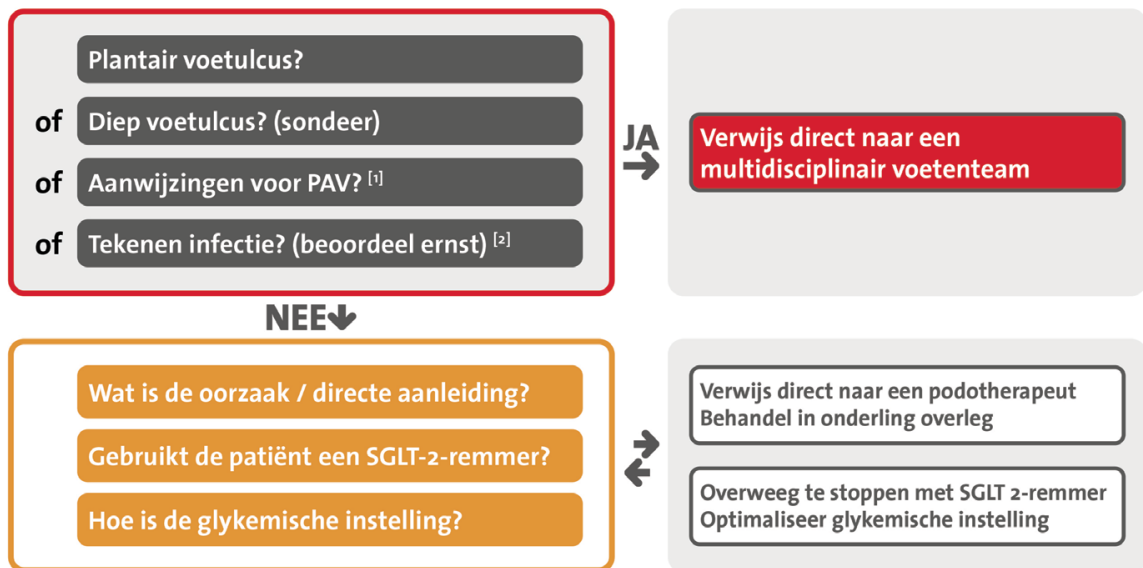

BIJ GEEN GENEZING BINNEN TWEE WEKEN: VERWIJS ALSNOG DIRECT NAAR MULTIDISCIPLINAIR VOETENTEAM

Multidisciplinair(e) voetenteam(s) en podotherapeuten:
[1] Aanwijzingen voor perifeer arterieel vaatlijden (PAV) zijn:

- Voorgeschiedenis: eerdere amputatie of vaatoperatie/PTA, eerdere Enkel-armindex (EAI) <0.9 OF: - Claudicatieklachten bij anamnese OF

- Onderzoek: EAl <0.9, Teen-armin$\operatorname{dex}(\mathrm{TAl})<0.75$, mono- of bifasisch Doppler, afwezige pulsaties

\section{[2] Tekenen van infectie:}

- Milde infectie, gekenmerkt door infectie van alléén de huid of sub. cutaan weefsel (zonder dat dieper weefsel aangedaan is), roodheid syston systemische tekenen van infectie. ingsfrequentie 22 /minut Beleid:verwijzing nar multidisci plinairvoetenteam of multidisciplinair (flucloxacillino ant antibi10-14 (agen) met herbeordeling 48 uur Bij geen verbetering bij deze 48 uur. Bijgeen verbetering bij deze tering of geen genezing binnen 2 tering of gerwiss alsnog monen 2 (telefonisch) nar multidisciplinair voetenteam. voetenteam.

ike infectie méér dan een milde infectie: verwijs met spoed (tevoetenteam

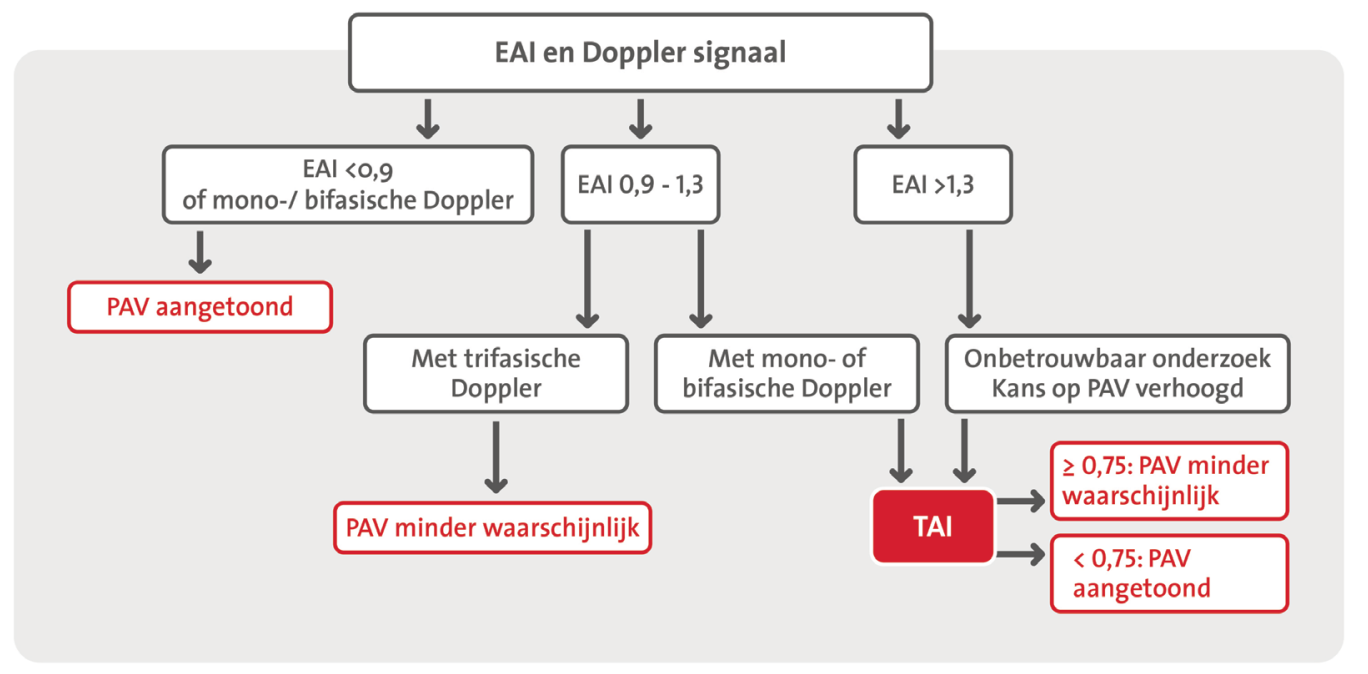

EAI: enkel-armindex $\cdot$ TAl: teen-armindex $\cdot$ PAV: perifeer arterieel vaatlijden

3). Oppervlakkige niet-plantaire ulcera, zonder tekenen van ischemie en zonder tekenen van een duidelijke infectie, kunnen in de eerste lijn behandeld worden. De overige patiënten dienen door een multidisciplinair voetenteam in het ziekenhuis behandeld te worden. In geval van pre-ulcera of overmatig eelt of van interventies zoals orthesen of 


\section{ADVIES PER SIMS-CLASSIFICATIE}

- Sims 0 - laag risico: eenmaal per jaar voetonderzoek onder verantwoordelijkheid van de huisarts, internist of specialist ouderengeneeskunde.

- Sims 1 - licht verhoogd risico: naast jaarlijks voetonderzoek na zes maanden extra voetcontrole door praktijkondersteuner, diabetesverpleegkundige, (diabetes)podotherapeut of medisch pedicure.

- Sims 2 - hoog risico: viermaal per jaar voetonderzoek/voetcontrole door (diabetes)podotherapeut.

- Sims 3 - sterk verhoogd risico: elke één tot drie maanden voetonderzoek/voetcontrole door (diabetes)podotherapeut of voetenteam.

schoeiselaanpassing(en) zal fysiek contact onvermijdelijk zijn. Het is raadzaam vooraf de angst voor besmetting bespreekbaar te maken en de patiënt te motiveren op de afspraak te komen. Bij een nieuw, bestaand of recidiverend voetulcus dient de patiënt te allen tijde door de behandelaar gezien te worden, omdat er dan essentiële handelingen met betrekking tot lichamelijk onderzoek verricht moeten worden, zoals een Doppler-meting of een meting van de enkel-armindex, of beoordeling van de diepte van het voetulcus door middel van sondage of aanvullend onderzoek. Indien zorg op afstand nodig is, kan dat verantwoord worden gedaan met behulp van beeldbellen en foto's (zie ook https://iwgdfguidelines.org/covid-19/).

\section{NDF-MODULE SAMENWERKINGSAFSPRAKEN DIABETISCHE VOET}

Vervolgens is de oorspronkelijke opdracht weer opgepakt en is gewerkt aan de NDF-module Samenwerkingsafspraken Diabetische Voet. Voor zorgverleners in de eerste en tweede lijn die direct of indirect te maken hebben met de voetverzorging van mensen met diabetes - huisartsen, praktijkondersteuners, diabetesverpleegkundigen, internisten, medisch pedicures, podotherapeuten, revalidatieartsen en vaatchirurgen - is het raamwerk vertaald naar vier praktische tools die helpen bij het maken van lokale/ regionale samenwerkingsafspraken. Het raamwerk is geautoriseerd door de betrokken verenigingen en is daarmee onderdeel van de NDF-zorgstandaard Diabetes.

De tools bestaan uit:

- een spreekkamerkaart Preventieve voetzorg (zie figuur 1);

- een online flowchart Preventieve voetzorg;

- een spreekkamerkaart Eerste hulp bij een diabetisch voetulcus (zie figuur 2);

- een online flowchart Eerste hulp bij een diabetisch voetulcus.

De twee flowcharts vormen de basis voor de binnen de keten te maken samenwerkingsafspraken. De flowcharts bieden via een interactieve webpagina aanvullende, verdiepende informatie.

\section{IMPLEMENTATIEPLAN}

Het bijbehorende implementatieplan is op dit moment nog in ontwikkeling en beschrijft een groot aantal acties die uitgevoerd moeten worden om de kwaliteit van de diabetische voetzorg en de daarvoor benodigde samenwerking tussen de verschillende professionals te verbeteren. Belangrijke issues die daarbij onder andere aan de orde komen, zijn ketenregie, diabetische voetzorg in verpleeghuizen en data voor monitoring. Het plan biedt handvatten om in de komende jaren met alle stakeholders samen te monitoren of de beschreven acties ook daadwerkelijk een gevolg hebben gekregen.

Binnenkort komt een NDF-nascholing beschikbaar die zorgverleners helpt bij de duiding en het gebruik van de opgeleverde producten. Informatie over deze scholing zal te zijner tijd ook beschikbaar zijn via: https://diabetesfederatie.nl/ndf-toolkit-persoonsgerichte-diabeteszorg/diabetische-voetzorg

\section{CONCLUSIE}

Een geïntegreerde aanpak die bestaat uit vroege opsporing van een voet 'at risk', multidisciplinaire behandeling, aandacht voor educatie van zowel zorgverleners als patiënten en intensieve voetzorg kan leiden tot een aanzienlijke reductie van het aantal amputaties.

De genoemde en andere voetzorgondersteunende tools zijn terug te vinden in de NDF-toolkit Persoonsgerichte Zorg en Preventie: https://diabetesfederatie.nl/ndf-toolkitpersoonsgerichte-diabeteszorg/diabetische-voetzorg

\section{REFERENTIES}

1 Nationaal Kompas Volksgezondheid, 2016.

2 Muller I. Foot Ulceration and Lower Limb Amputation in Type 2 Diabetic Patients in Dutch Primary Health Care. Diabetes Care 2002 Mar; 25(3): 570-574.

3 Ragnarson G. Health-related quality of life in patients with diabetes mellitus and foot ulcers. J Diabetes Complications, Sep-Oct 2000;14(5):235-41. doi: 10.1016/s1056-8727(00)00133-1.

4 Prompers L. Prediction of outcome in individuals with diabetic foot ulcers: focus on the differences between individuals with and without peripheral arterial disease. The EURODIALE Study. Diabetologia, 2008 May; 51(5): 747-755. doi: 10.1007/s00125-008-0940-0.

5 Zie: https://diabetesfederatie.nl/nieuwsberichten/779multidisciplinaire-leidraad-voetzorg-ten-tijde-van-covid-19.

${ }^{*}$ Diabetesvereniging Nederland (DVN), Diabetes Huisartsen Advies Groep (DiHAG), Nederlandse Vereniging van Podotherapeuten (NVvP), Nederlandse Vereniging van Diabetes Podotherapeuten (NVvDP), Verpleegkundigen en Verzorgenden Nederland Diabetes (V\&VN Diabetes), Nederlandse Internisten Vereniging, Diabeteskamer (NIV), Nederlandse Vereniging van Revalidatieartsen (VRA), Nederlandse Vereniging voor Vaatchirurgie (NVVV), ProVoet (Brancheorganisatie medisch pedicures), Orthopedische schoenmakers 